(2) Open Access Full Text Article

\title{
Miniaturized high-resolution wide-field contact lens for panretinal photocoagulation
}

This article was published in the following Dove Press journal:

Clinical Ophthalmology

07 April 2014

Number of times this article has been viewed

\section{Keyvan Koushan \\ KV Chalam}

Department of Ophthalmology, University of Florida College of Medicine, Jacksonville, FL, USA
Correspondence: KV Chalam 580 W 8th Street, Tower II, 3rd Floor, Jacksonville, FL 32209, USA

Tel + I 904244936 I

Fax + I 9042449391

Email kakarla.chalam@jax.ufl.edu
Background and objective: We describe a miniaturized lightweight high-refractive-index panretinal contact lens for diagnostic and therapeutic visualization of the peripheral retina.

Instrument design: The miniaturized high-resolution wide-field contact lens includes three optical elements in a light $(15 \mathrm{~g})$ and miniaturized (16 mm footplate, $24 \mathrm{~mm}$ external aperture, and $21 \mathrm{~mm}$ vertical height) casing contributing to a total dioptric power of +171 diopters. This lens provides up to $165^{\circ}$ visualization of the retina for diagnostic and therapeutic applications while allowing easier placement due to its miniaturization.

Conclusion: This new lens (50\% lighter and 89\% smaller) improves upon earlier contact lenses for visualization of the peripheral retina.

Keywords: contact lens, panretinal photocoagulation, retinal examination, peripheral retina, high resolution view, wide-angle lens, lens

\section{Introduction}

Detailed evaluation of the peripheral retina is one of the challenging parts of the ophthalmic examination. Handheld contact lenses are essential for examination of peripheral retina as well as for delivery of laser photocoagulation to treat diseases such as proliferative diabetic retinopathy and retinal breaks that affect the peripheral retina. Different generations of contact lenses have been successively designed to improve the quality of the peripheral fundus view during examination and surgery while minimizing image distortion. ${ }^{1-5}$

However, currently available lens systems are bulky, adding discomfort to the procedure and requiring superior skills, as the pupil, the lens, and the operator have to be coaxial to obtain a good-quality image. In this report, we describe the optical design of a novel miniaturized lightweight contact lens system for panretinal photocoagulation (PRP), and compare it with the SuperQuad 160 lens system (Volk Optical, Inc., Mentor, OH, USA).

\section{Description of the instrument}

The miniaturized high-resolution (HR) wide-field contact lens (Volk Optical, Inc.) includes three optical elements that are affixed in their positions in a plastic casing. Starting from the patient's cornea, the three elements are: (1) a polymer meniscus lens with index of refraction of 1.49 , thickness of $0.5 \mathrm{~mm}$, and nominal apex radii of $-7.8 \mathrm{~mm}$ (concave) and $+7.8 \mathrm{~mm}$ (convex); (2) a glass meniscus lens with index of 1.88 , thickness of $5 \mathrm{~mm}$, and nominal apex radii of $-7.8 \mathrm{~mm}$ and $+5.3 \mathrm{~mm}$; and (3) a double-convex glass lens with index of 1.44 , thickness of $10.5 \mathrm{~mm}$, and nominal apex radii of $18 \mathrm{~mm}$ and $17.3 \mathrm{~mm}$. The total dioptric power of this lens is +171 diopters, forming a real aerial image at the distance of $5.8 \mathrm{~mm}$ from its focal plane between the 
lens and the microscope (Figure 1A). This compact design reduces the weight of the lens and allows better stability on the eye during diagnostic or therapeutic procedures.

In our clinical practice so far, we have used the HR Wide Field contact lens in performing over 40 successful PRP procedures. The lens has provided excellent view of the peripheral retina, obviating the need for application of laser indirect ophthalmoscopy to reach very peripheral retina. Combined with instructing patients on proper gaze position, this lens has enabled us to apply PRP burns as far peripheral as just anterior to the ora serrata.

\section{Discussion}

Visualization of the peripheral retina is vital for detailed examination of the retina as well as for delivery of PRP in proliferative retinal diseases. Various contact and noncontact lens systems are available to enhance the visualization of the retina for these purposes. ${ }^{1-6}$ The previous generation of wide-field contact lens systems (SuperQuad 160) uses a wider aperture to expand the field of view. This leads to an inherent difficulty in using the lens due to its bulky design. The SuperQuad 160 lens has two optical elements: (1) polymer meniscus with index of 1.49 , thickness of $3 \mathrm{~mm}$, and normal apex radii $-7.6 \mathrm{~mm}$ and $+7 \mathrm{~mm}$; (2) double-convex glass element with index of 1.79 , thickness of 9.3 , and nominal apex radii of $15.8 \mathrm{~mm}$ and $10.5 \mathrm{~mm}$. The total dioptric power of this lens is 126 diopters, forming a real aerial image at the distance of $7.9 \mathrm{~mm}$ from its focal plane (Figure 1B). Figure 2 shows the comparative dimensions of the miniaturized HR wide field lens and the SuperQuad 160 lens. The latter offers the same width of field, but is considerably larger and more difficult to hold in position (see Table 1).

On patients with narrow palpebral fissures, the smaller size and weight of the HR wide field lens allow easier placement and more stability on the patient's eye (Figure 3 ). The HR wide field lens is 50\% lighter, 30\% shorter, with an external aperture $89 \%$ smaller compared with the SuperQuad 160. The lighter weight (15 g) translates into more stability of the lens placement on the cornea for the duration of the photocoagulation. In addition, the shorter focal distance with the shorter footplate-to-external aperture distance of this lens facilitate easier optical alignment of all components of the indirect viewing system of the fundus (ie, the contact lens, the aerial image, and the condensing lens of the slit lamp), providing easier visualization of the fundus during PRP (Figure 1). The shorter alignment system provides better stability of the system, making small movements inconsequential for image quality.

An effective way to reduce the overall dimensions of a multiple lens system, while preserving its width of view, is increasing the dioptric power of the lens, thereby gathering
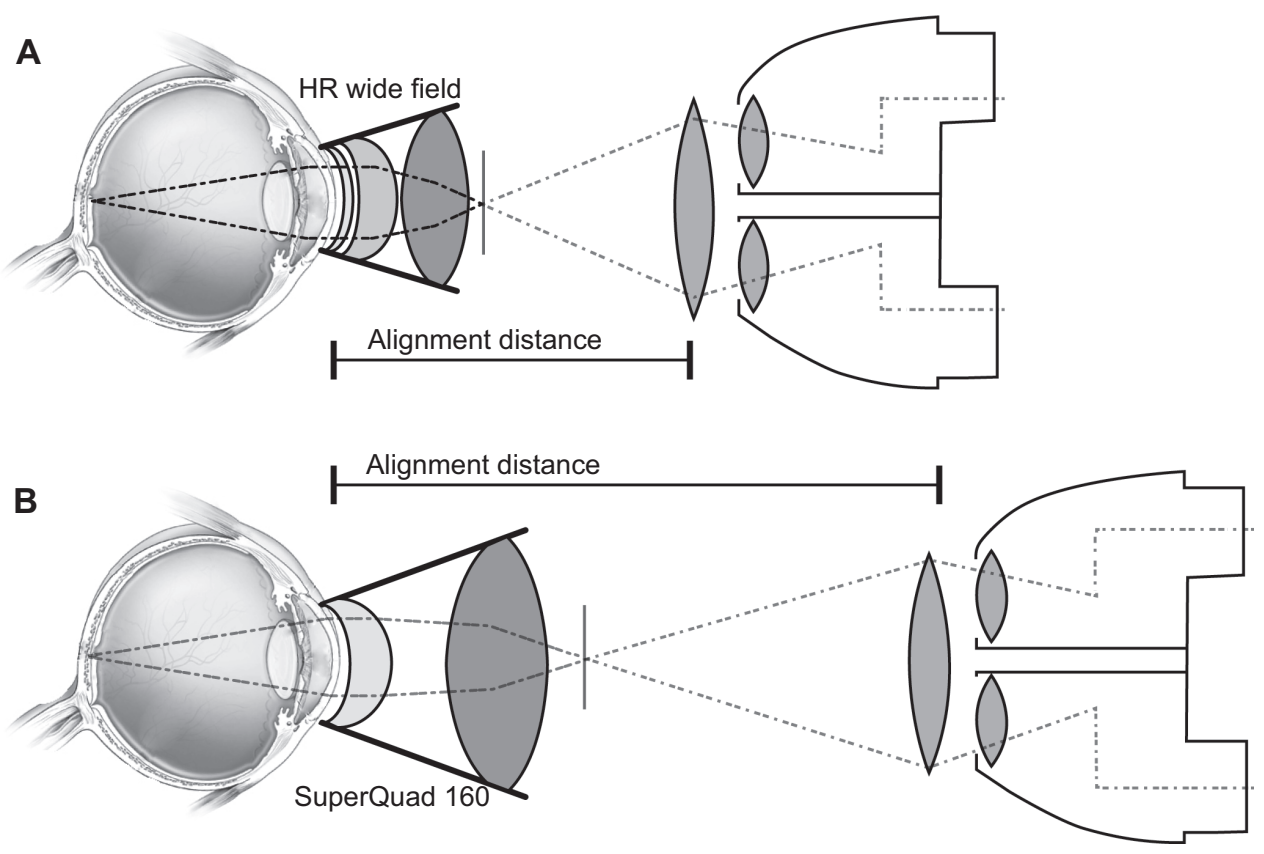

Figure I Optical alignment of the viewing systems.

Notes: The smaller size of the HR wide field lens translates into a shorter alignment distance of the optical components of the indirect viewing system, resulting in better image stability. (A) Indirect viewing system with a shorter alignment distance when using the HR wide field lens (Volk Optical, Inc., Mentor, OH, USA). (B) Indirect viewing system with a longer alignment distance when using the SuperQuad 160 lens system (Volk Optical, Inc.).

Abbreviation: HR, high-resolution. 


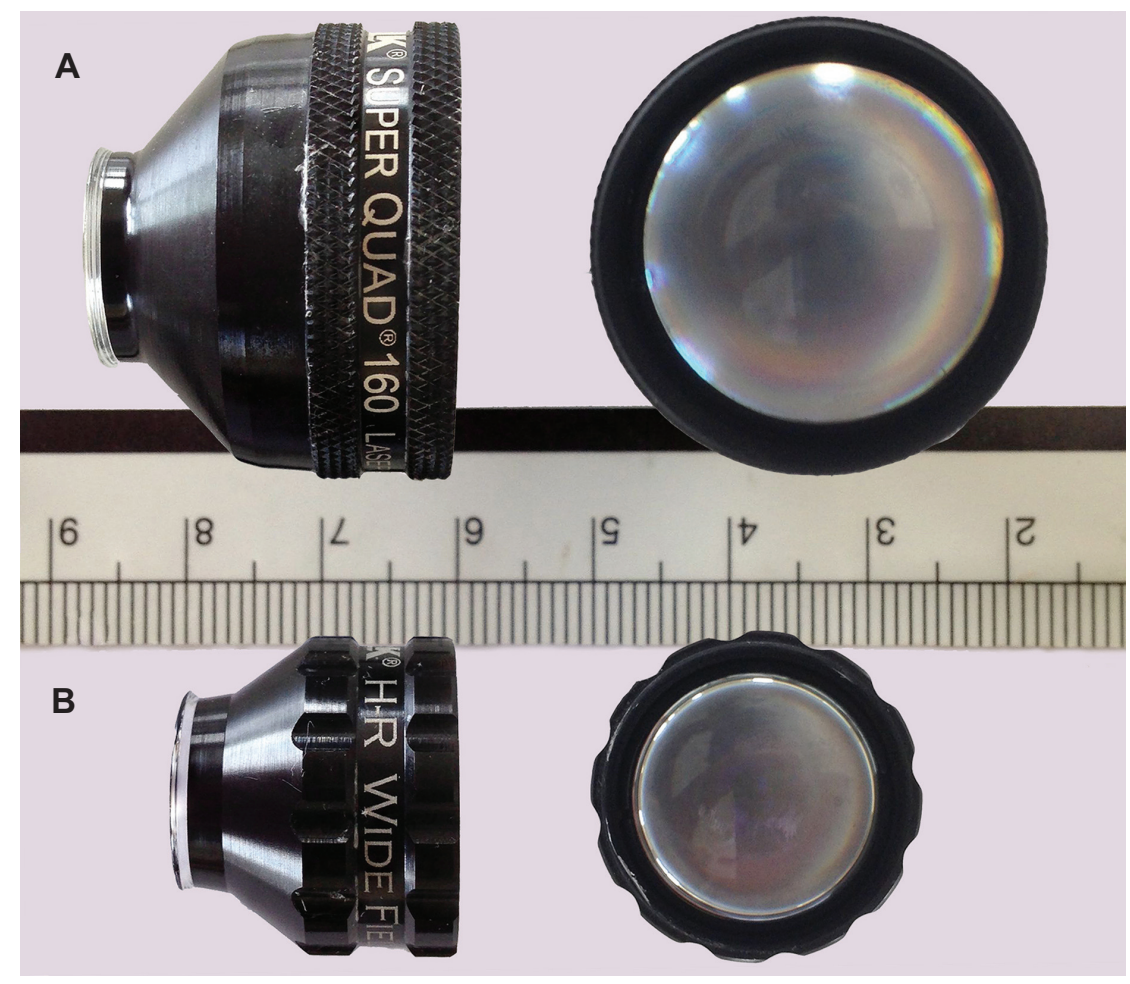

Figure 2 Comparison of the sizes of the lenses.

Notes: Comparison of the sizes of the SuperQuad I60 (Volk Optical, Inc., Mentor, OH, USA) (A), and (B) the HR wide field (Volk Optical, Inc.) contact lenses. The newer miniaturized HR wide field lens is significantly less bulky.

Abbreviation: $\mathrm{HR}$, high-resolution.

more peripheral rays of light from the peripheral retina. The new HR wide field lens uses this principle by maximizing the dioptric power of the lens through utilization of highrefractive-index glass, and thereby reducing the overall size of the instrument. The use of a high-index lens also reduces the aberrations associated with any lens system.

In our experience, the peripheral retinal view obtained with the miniaturized HR Wide Field lens has the same optical clarity as obtained with the SuperQuad 160 lens. The novel design of this low weight, miniaturized, wide-field lens allows HR peripheral retinal visualization, and most likely increases patients' comfort compared with previous generations of wide-field contact lenses. In addition, the reduced-size profile of the lens simplifies manipulation of the lens within the orbit leading to shortened procedure time. This lens is particularly useful in treating patients with small or deep orbital sockets (such as very young patients) where larger lenses are difficult to apply and maintain on the ocular surface.

\section{Conclusion}

In summary, we describe a miniaturized lens that is $50 \%$ lighter, $28 \%$ shorter, and $89 \%$ smaller than a

Table I Comparative dimensions and optical properties of the HR Wide Field (Volk Optical, Inc., Mentor, OH, USA) and the SuperQuad I 60 (Volk Optical, Inc.) contact lenses. While preserving the same field of view, the newer miniaturized lens is lighter with smaller dimensions

\begin{tabular}{llll}
\hline Characteristic & HR wide field & SuperQuad 160 & Difference \\
\hline Field of view & $160^{\circ} / 165^{\circ}$ & $160^{\circ} / 165^{\circ}$ & 0 \\
Image magnification & $0.5 \times$ & $0.5 \times$ & 0 \\
Laser spot & $2.0 \times$ & $2.0 \times$ & 0 \\
Lens footplate (diameter) & $16 \mathrm{~mm}$ & $16 \mathrm{~mm}$ & 0 \\
External aperture (diameter) & $24 \mathrm{~mm}$ & $33 \mathrm{~mm}$ & $37 \%$ \\
External aperture (area) & $452 \mathrm{~mm}^{2}$ & $855 \mathrm{~mm}^{2}$ & $89 \%$ \\
Vertical height & $21 \mathrm{~mm}$ & $27 \mathrm{~mm}^{2}$ & $28 \%$ \\
Weight & $15 \mathrm{~g}$ & $22 \mathrm{~g}$ & $50 \%$ \\
\hline
\end{tabular}

Abbreviation: HR, high-resolution. 

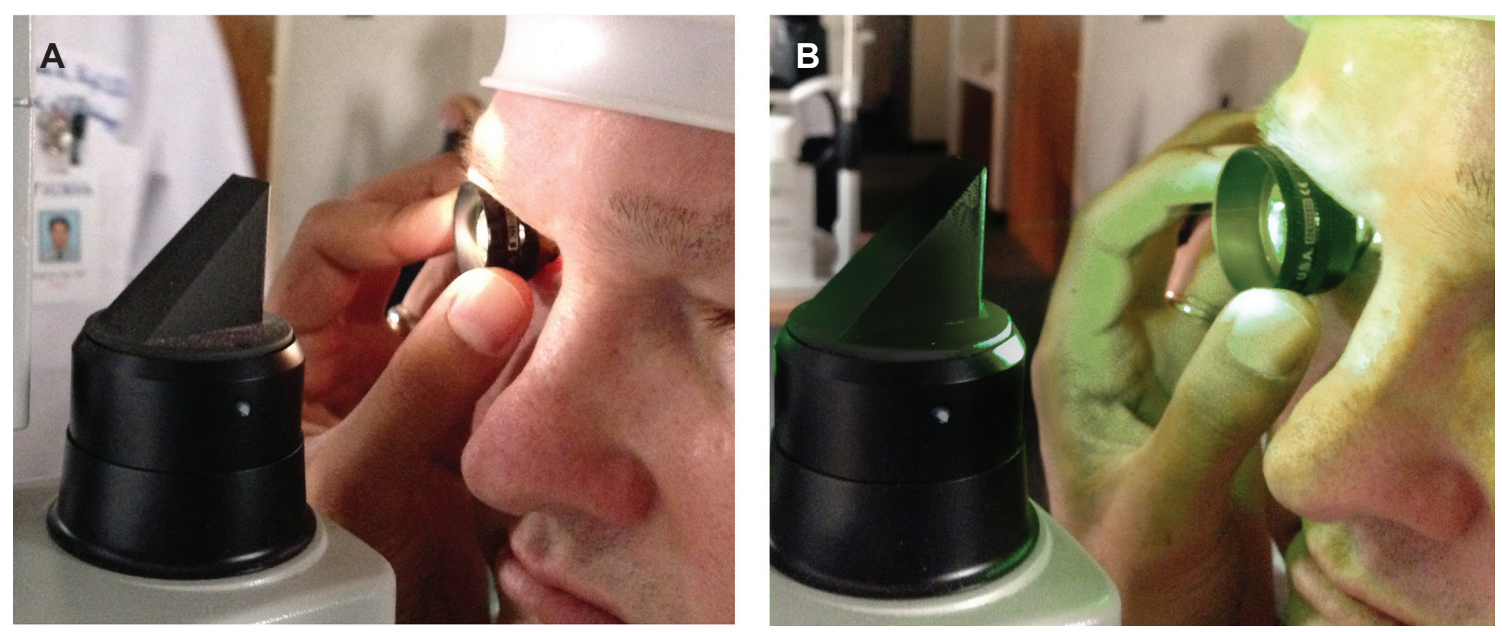

Figure 3 Comparison of lens placement.

Notes: In patients with smaller orbits or deep orbital sockets, the HR Wide Field lens (Volk Optical, Inc., Mentor, OH, USA) (A) allows easier lens placement compared with the SuperQuad 160 lens (Volk Optical, Inc.) (B).

Abbreviation: $\mathrm{HR}$, high-resolution.

conventional panretinal lens for viewing peripheral retina. The HR wide field lens improves upon earlier panretinal contact lenses for visualization of the peripheral retina with minimal distortion. The HR Wide Field lens provides superior view of peripheral retina for diagnostic and therapeutic applications. The smaller size likely translates into more comfort for the patient.

\section{Disclosure}

The authors have no proprietary or financial interest in the content of this manuscript. The content of this manuscript was presented as a poster presentation at the 2013 American Society of Retina Specialists annual meeting in Toronto, Canada.

\section{References}

1. Murthy RK, Brar VS, Chalam KV. Evaluation of ultra wide angle "ora-ora" high refractive index self-stabilizing contact lens for vitreous surgery. Retina. 2010;30(9):1551-1553.

2. Chalam KV, McLauchlan T, Khetpal V, Murthy RK. New miniaturized contact lens for wide-angle fundus fluorescein angiography: wide-angle fluorescein angiography lens. Retina. 2012;32(3):640-642.

3. Murthy RK, Chalam KV. Assistant-independent OptiFlex system for contact and noncontact wide-angle viewing in vitreoretinal surgery. Arch Ophthalmol. 2010;128(4):490-492.

4. Staurenghi G, Viola F, Mainster MA, Graham RD, Harrington PG. Scanning laser ophthalmoscopy and angiography with a wide-field contact lens system. Arch Ophthalmol. 2005;123(2):244-252.

5. Ozerdem U, Freeman WR, Bartsch DU, Clark TM. A simple noncontact wide-angle fundus photography procedure for clinical and research use. Retina. 2001;21(2):189-190.

6. Sharma G, Purkayastha S, Deka H, Bhattacharjee H. Commonly used diagnostic and laser lenses for retinal diseases - an overview. DOS Times. 2008;13(9):49-50.
Clinical Ophthalmology

\section{Publish your work in this journal}

Clinical Ophthalmology is an international, peer-reviewed journal covering all subspecialties within ophthalmology. Key topics include: Optometry; Visual science; Pharmacology and drug therapy in eye diseases; Basic Sciences; Primary and Secondary eye care; Patient Safety and Quality of Care Improvements. This journal is indexed on

\section{Dovepress}

PubMed Central and CAS, and is the official journal of The Society of Clinical Ophthalmology (SCO). The manuscript management system is completely online and includes a very quick and fair peer-review system, which is all easy to use. Visit http://www.dovepress.com/ testimonials.php to read real quotes from published authors. 